\title{
Gas to displace coal on road to clean energy
}

Vast newly discovered reserves of natural gas could help the United States move to a low-carbon future, says a report by researchers at the Massachusetts Institute of Technology (MIT) in Cambridge.

The assessment - The Future of Natural Gas - estimates that the United States could reduce greenhouse-gas emissions from the electricity sector by at least $10 \%$ by shutting down the least efficient coal-fired plants and ramping up existing gas-powered generators that are running below capacity. Gas-fired plants emit roughly half as much carbon dioxide as equivalent coal stations.

The report estimates the US natural-gas reserves at about 60 trillion cubic metres, enough to fuel the country for 92 years at 2009 consumption levels. That puts the United States behind only Russia and the Middle East in terms of supply - a dramatic contrast to a decade ago, when falling production rates triggered gas price

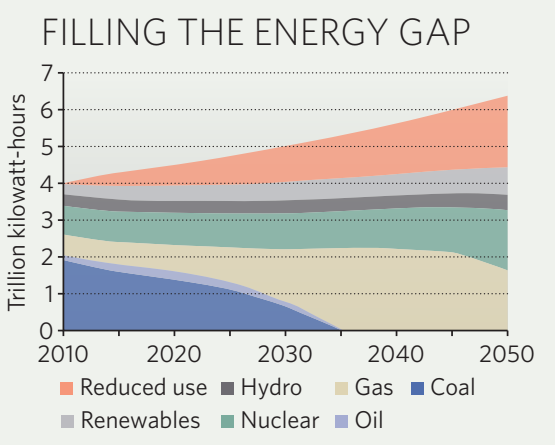

spikes and speculation that the United States would be forced to import large quantities of liquefied natural gas. The greatest potential for growth, says the report, is in electricity production, although natural gas could also be deployed to fuel fleet vehicles, buses and long-haul trucks.

The study found that with a 'level playing field' approach to energy pricing, in which the prices of energy sources are set to reflect the carbon dioxide they produce, gas could almost entirely displace coal burning in the United States by 2035 (see 'Filling the energy gap'). Under such a system, naturalgas consumption would begin to taper off in 2045 because of the need to limit all sources of carbon, but gas could play a vital part as a bridge to renewable sources of energy, says Ernest Moniz, director of the MIT Energy Initiative, who led the assessment team.

Although there are no technical barriers, the challenge is getting the monetary incentives or regulations in place to help gas displace coal, says Mark Thurber, associate director for research at the Program on Energy and Sustainable Development at Stanford University in California. "The next discussion should be, 'how do we do it?"” Jeff Tollefson

See go.nature.com/YDLXXS for a longer version of this story. 